\title{
Afet Yönetimi Sürecinde Risk Algısı Çalışmalarının Katkısı
}

\author{
Sefa MIZRAK ${ }^{1}$
}

\section{Özet}

Afetleri önlemek ve afetlerin zararlarını azaltmak için birçok yapısal ve yapısal olmayan çalışma yürütülmektedir. Özellikle afetler ve afetlerin olası sonuçları hakkında insanların düşüncelerini anlamak afet risk azaltma çalışmaları için önemlidir. Çünkü, insanların düşünceleri afetlere karşı koruyucu önlem alma davranışlarını etkilemektedir. Bu çalışmanın amacı, afetlerle ilgili yürütülen bilimsel risk algısı çalışmalarının afet yönetimi açısından önemini ortaya çıkarmaktır. Çalışma literatür taraması olarak yapılandırılmıştır. Bilim insanları farklı afet türlerine karşı insanların risk algılarını ve risk algısını etkileyen faktörleri yaygın bir şekilde araştırmışlardır. İnsanların afet risk algıları afetler ile ilgili algıladıkları korku, endişe, depresyon, anksiyete, maddi veya bireysel zarar görme olasılı̆̆ı, bilgi, müdahale kapasitesine güven, afetin şiddeti, sıklığı ve etkisinin büyüklüğüne göre belirlenmiştir. Sosyo-demografik değişkenler arasından yaş, eğitim, ekonomik durum, afet tecrübesi ve afet risk algısı ilişkisi yaygın olarak araştırılmıştır. Afet risk algısı çalışmaları afet öncesi ve afet sonrası yönetim süreçlerinin daha iyi planlanması için gereklidir. Bu nedenle bilim insanları ve afet yönetiminden sorumlu kişiler toplumun afet risk algısını bütün afetler için kapsamlı bir şekilde araştırmalıdır.

Anahtar Kelimeler: Afet, Risk, Risk Algısı, Afet Risk Algısı

\section{Contribution of risk perception studies in disaster management process}

\begin{abstract}
Many structural and non-structural measures are conducted to prevent disasters and reduce their damages. In particular, understanding people's thoughts related to disasters and their possible consequences is important for disaster risk reduction studies. Because, people's thoughts affect their behaviors to take protective measures against disasters. The objective of this study is to reveal the importance of scientific risk perception studies conducted on disasters in terms of disaster management. The study was designed as a literature review. Scientists have extensively investigated people's risk perceptions against different types of disasters and the factors affecting risk perception. Disaster risk perceptions of people were determined according to their perceived fear, worry, depression, anxiety, possibility of material or individual damage, knowledge, confidence in response capacity, severity, frequency and magnitude of the impact of disasters. Among the socio-demographic variables, the relationship between age, education, economic status, disaster experience and disaster risk perception has been widely investigated. Disaster risk perception studies are necessary for better planning pre-disaster and post-disaster management processes. Therefore, scientists and people responsible for disaster management should comprehensively investigate the disaster risk perception of the community for all disasters.
\end{abstract}

${ }^{1}$ Arş. Gör., Gümüşhane Üniversitesi, Acil Yardım ve Afet Yönetimi Bölümü, Gümüşhane e-Posta: sefamizrak1@gmail.com ORCID: 0000-0002-3751-131X 
Keywords: Disaster, Risk, Risk Perception, Disaster Risk Perception

\section{GİRIş}

Doğa olayları ve teknolojik problemler sonucu oluşan afetler sağlığa, ekonomiye ve çevreye zarar vermektedir. Örneğin, 2000 ve 2019 yılları arasında, depremler tüm dünyada 721318 kişinin ölümüne ve aşırı sıcaklar ise 165923 kişinin ölümüne neden olmuştur (URL 1). Diğer yandan afetler ülke ekonomisine, beșerî sermayeye, kalkınma planlarına, ekonomik düzene, ihracat ve ithalat dengesine zarar vermektedir (Akar, 2013).

COVID-19 salgınının neden olduğu pandemi tüm dünyada insan gücünü ve ekonomik işlemleri olumsuz etkilediği için küresel düzeyde ekonomiye zarar vermiştir (Padhan ve Prabheesh, 2021). 2011 yılında Van'da meydana gelen deprem yakın bölgede birçok heyelanı tetiklemiştir (Görüm, 2016). Afetlerden etkilenen insanların çoğunda afetlerden sonra uyum problemleri, travma sonrası stres bozukluğu, depresyon, panik rahatsızlıklar ve somatik şikayetler ortaya çıkmaktadır (Math vd., 2008). Afetler yüzünden birçok insan uzun yıllardır yaşadığı bölgeyi geçici bir süreliğine veya tamamen terk etmek zorunda kalmaktadır (Tercan, 2018). Afetlerin etkisinin, sayısının ve şiddetinin artması yerel, ulusal ve uluslararası düzeyde afet risk yönetimi politikalarının sürekli güncellenmesi ve geliştirilmesi gerektiğini göstermektedir.

Afet risk yönetimi afet olasılığını ve tehlikelerin olumsuz etkilerini azaltmak için gerekli politikaların ve stratejilerin uygulandığı bir süreçtir (URL 2). Risk yönetimi çalışmalarının başarılı olması için insanların riskleri nasıl algıladıklarını anlamak gerekmektedir (Prabhakar, Srinivasan ve Shaw, 2009). İnsanların risk algısı afet risklerini azaltmada önemli bir rol oynamaktadır (Qasim vd., 2015). Risk algısı çalışmaları tehlike ile ilgili insanların farkındalıklarını, duygularını ve davranışlarını araştırmaktadır (Kellens vd., 2011). İnsanların riski algılama özellikleri davranışlarını etkilediği için kamu politikaları insanların ne düşündüğüne ve ne hissettiğine göre düzenlenmelidir (Donahue, Eckel ve Wilson, 2014).

Afetlerin neden olduğu zararın artması ile birlikte afet politikalarında risk azaltma ve risk yönetimi daha fazla önem kazanmıştır (Azimli Çilingir ve Örçen Güler, 2020). Ulusal ve uluslararası düzeyde afetlerin etkilerini azaltmak için tasarlanan Sendai Eylem Planı afet risklerini anlamayı öncelikli olarak ele almaktadır ve afet risk yönetimi politikaları için afet risklerinin anlaşılmasının önemini vurgulamaktadır (URL 3). Türkiye'de Afet ve Acil Durum Yönetimi Başkanlığı 2019-2023 ulusal stratejik planında risk odaklı afet yönetimi anlayışının bütün sektörlerde benimsenmesini sağlamayı hedeflemektedir (URL 4). Diğer yandan, Afet ve Acil Durum Yönetimi Başkanlığı Türkiye'de illerde afet risklerini azaltmak ve risk azaltma bilincini oluşturmak için İl Afet Risk Azaltma Planı'nı tasarlamıştır (URL 5). Bu çalışmanın amacı, afetlerle ilgili risk algısı çalışmalarının afet yönetimindeki önemini ortaya çıkarmaktır. Bu çalışmanın risk, risk algısı ve afet algısı alanında çalışan bilim insanlarına ve afet yöneticilerine rehber olması beklenmektedir.

\section{RİSK VE RİSK ALGISI}

Risk kavramının farklı alanlarda birçok tanımı bulunmaktadır. Türk Dil Kurumu riski zarara uğrama tehlikesi olarak tanımlamaktadır (URL 6). Risk bir olayın meydana gelme olasılı̆g ve muhtemel sonuçlarıdır (Jóhannesdóttir ve Gísladóttir, 2010). Risk negatif bir olayın gerçekleşme olasılığıdır (Bourque vd., 2013). Afet ve Acil Durum Başkanlığı'na göre risk, bir olayın can kaybına, ekonomik ve çevresel kayıplara neden olma olasılı̆̆ıdır ve potansiyel kayıplardır (URL 7). Risk felaket öngörüsü olarak da tanımlanmaktadır (Beck, 2011). 
Doğa ve teknoloji kaynaklı afetlerde ise risk ölümcül tehdit, kader ve erken uyarı göstergesi gibi durumları da ifade etmektedir (Renn, 2004). İş Sağlığı ve Güvenliği Kanunu riski, tehlikenin neden olabileceği kayıp, yaralanma veya başka zararlı sonuç ihtimali olarak ifade etmektedir (URL 8). Her alanda farklı risklerin olumsuz veya olumlu farklı sonuçları olduğu için insanlar risk kavramını farklı șekillerde yorumlamaktadır ve riske karşı farklı duygu, düşünce, bilgi ve tutuma sahiptirler.

Risk algısı insanların karşılaştıkları tehlikelerin etkilerine karşı algıladıkları kişisel bir yargıdır (Gierlach, Belsher ve Beutler, 2010). Risk algısı, herhangi bir tehlikenin etkilerine karşı algılanan olasıllk ve bu tehlikenin etkilerinin algılanma şiddetidir (Becker, Aerts ve Huitema, 2014). Belirli bir olay veya eylemin etkilerine karşı insanların algıladıkları olasılık ve sonuçlar da risk algısıdır (Bubeck, Botzen ve Aerts, 2012). Kısacası, risk algısı insanların riski nasıl yorumladıkları ile ilgilidir ve risk algısı tehlikeye, bölgeye ve kültüre göre değişir (Kung ve Chen, 2012; O’Neill vd., 2016).

\section{AFET YÖNETIMINDE AFET RISSK ALGISI}

Afet yönetimi, afetlerin ve afet zararlarının azaltılması, afetlere hızlı ve etkili müdahale edilmesi, afet sonrasında daha güvenli ve gelişmiş bir ortam oluşturulması için gereken planlama yönlendirme, koordinasyon ve destekleme çalışmalarında tüm toplum, kurum ve kuruluşların dahil olduğu bir süreçtir (URL 7). Afet yönetimi başlıca hazırlık, zarar azaltma, müdahale ve iyileşme aşamalarından oluşmaktadır (Simonovic, 2011). Hazırlık ve zarar azaltma afet öncesi dönemde yapılan çalışmalardır. Müdahale ve iyileştirme çalışmaları afet meydana geldiği zaman başlar ve afet sona erene kadar devam eder.

Daha etkili ve verimli bir afet yönetimi için bilim insanları afetlere karşı insanların risk algılarını ve risk algılarını etkileyen faktörleri araştırmışlardır ve bu araştırmalar afetlerle ilgili geliştirilen politikalara yön verebilecek önemli sonuçlar ortaya çıkarmıştır (Tablo 1). Risk algısı farklı afet türlerine göre farklı bölgelerde çalışılmıştır ve bilim insanları afetlere karşı insanların risk algısı düzeyini ve risk algısı düzeyini etkileyen faktörleri araştırmışlardır. Araştırmalara göre insanların sosyo-demografik özellikleri ve kişisel özellikleri afet risk algısı üzerinde etkili olabilmektedir (Tablo 1). İnsanların risk algıları yaşamak için yer seçimlerini, tehlikelere karşı zarar azaltma ve koruyucu önlem almalarını etkilemektedir (Bardsley vd., 2018). Depreme karşı algılanan olasılık ve endișe insanların deprem sigortası yaptırma istekliliğini artırmaktadır (Xu vd., 2018).

İnsanların afet risk algısını araștırmak için afetlere karşı algılanan olumsuz düşünceler, afet meydana gelme olasılığı ve sıklığı, afetin ölü, yaralı ve ekonomik zarara neden olma potansiyeli ele alınmıştır. Örneğin, deprem risk algısını belirlemek için kadınların kendilerini kadın oldukları için depreme karşı hassas hissedip hissetmedikleri belirlenmiștir (Mızrak, Özdemir ve Aslan, 2021). Vatandaşların ve kamu görevlilerinin afet risk algısını belirlemek için toplumda büyük bir afetin meydana gelme olasılığının yüksekliği ve bir afetin etkisinin ne kadar şiddetli olabileceği tespit edilmiştir (Donahue, Eckel ve Wilson, 2014). Sel risk algısı insanların sele maruz kalmaları durumunda selin etkilerinden kendilerini koruyacak algllanan kapasitelerinin ve kaynaklarının yeterliliğe göre belirlenmiştir (Adelekan ve Asiyanbi, 2016). Tayfun afetine karşı risk algısını ölçmek için araştırmaya katılanların düşüncelerine göre afetin insan sağlığı ve maddi varlıklar üzerinde neden olabileceği zararın büyüklüğü ve insanların tayfuna karşı hissettikleri korkunun büyüklüğü araştırılmıştır (Zhang vd., 2017).

İnsanların afetlerle ilgili risk algıları hem belirli bir afet türüne karşı hem de genel olarak bütün afet türlerine karşı farklı șekillerde belirlenmiş ve yorumlanmıştır. Örneğin, sel ile ilgili insanların risk algısı sele karşı algılanan farkındalık, olasılık, etki ve korku boyutlarında belirlenmiştir ve 
cinsiyet, yaş, eğitim, yıllık gelir, hane halkı büyüklüğü, çocuk sahibi olma durumu, nehre uzaklık ve sel tecrübesi değişkenlerinin sel risk algısı üzerindeki etkisi araştırılmıştır (Liu vd., 2018). Öğrencilerin kampüste afetlere karşı algıladıkları riski belirlemek için ölçek geliştirilmiş ve afetlere karşı algılanan maruz kalma, etki ve kontrolsüzlük değişkenlerinin anksiyete üzerindeki etkisi belirlenmiştir (Mızrak ve Aslan, 2020). Brezilya'da heyelanın insanların hayatlarını, yaşam koşullarını, iyilik hallerini ne ölçüde tehdit ettiği, heyelanın insanların evlerine zarar verebilme ihtimali ve heyelanla bireysel ve kurumsal mücadele kapasitesi değerlendirilerek heyelan risk algısı tespit edilmiştir (Mendonca ve Gullo, 2020). Kasırga risk algısı için bilişsel ve duyuşsal faktörleri belirleyen ölçek geliştirilmiştir. Bu ölçek duyuşsal faktörde kasırganın insanları ne kadar endişelendirdiği, korkuttuğu, dehşete düşürdüğü ve depresif hissettirdiğini belirlemektedir. Bilişsel boyutta ise kasırganın neden olabileceği devasa yıkım, ölüm, finansal tehdit ve gelecek nesiller için tehlike büyüklüğü tespit edilmektedir (Trumbo vd., 2016). Çin'de depremin yaşandığı bölgede deprem risk algısı olasılık ve şiddet boyutlarında belirlenmiștir ve depreme karşı algılan olasılık ve şiddetin ve yaşanılan yere bağlılığın afet bölgesinden tahliye istekliliğine etkisi olup olmadığı araştırılmıştır (Xu vd., 2019).

Bilim insanları afetlere daha etkili mücadele edilebilmesi için afet risk algısı çalışmalarının önemini ve gerekliliğini vurgulamaktadırlar. Afetlere karşı daha dirençli toplumlar oluşturmak için gerekli olan planların, programların ve politikaların geliştirilmesi için insanların risk algısı araştırılmalıdır (Bronfman vd., 2016). İnsanların depremden önce ve sonra psikolojik olarak desteklenmesi için insanların riskleri nasıl algıladıklarını ortaya çıkarmak önemlidir (Kung ve Chen, 2012). İklim değişikliği ve insanların yerel çevre risk algısı arasındaki ilişkiyi anlamak uygun risk iletişiminin kurulmasını sağlayacaktır (Bardsley vd., 2018). Herhangi bir afetin öncesinde, afet meydana geldiği anda ve afet sonrasında insanların maruz kaldığı riski artıran faktörlerin araştırılması afetin toplum üzerindeki etkisinin daha iyi anlaşılmasını sağlayabilmektedir (Kalaycioğlu, 2018).

Tablo 1. Afetlerle ilgili yürütülen risk algısı çalışmaları

\begin{tabular}{|c|c|c|c|}
\hline Yazarlar & $\begin{array}{c}\text { Çalışma } \\
\text { Alanı } \\
\end{array}$ & Amaç & Sonuç \\
\hline $\begin{array}{l}\text { (T. Liu, } \\
\text { Zhang, Li ve } \\
\text { Zhang, 2020) }\end{array}$ & $\begin{array}{l}\text { Çin'de altı } \\
\text { şehir }\end{array}$ & $\begin{array}{l}\text { Halkın } \quad \text { tehlikeli } \\
\text { kimyasallara karşı risk } \\
\text { algısını } \quad \text { etkileyen } \\
\text { faktörleri araştırmak. }\end{array}$ & $\begin{array}{l}\text { Demografik değişkenler arasından sadece } \\
\text { cinsiyet risk algısını anlamlı olarak } \\
\text { etkilemektedir ve erkeklerin risk algısı } \\
\text { kadınlardan daha yüksektir. Güven değişkeni } \\
\text { risk algısını anlamlı olarak azaltıyorken, } \\
\text { afetlerle ilgili beceri, sorumluluk ve bilgi } \\
\text { değișkenleri risk algısını anlamlı olarak } \\
\text { artırmaktadır. }\end{array}$ \\
\hline $\begin{array}{l}\text { (Becker, } \\
\text { Aerts ve } \\
\text { Huitema, } \\
\text { 2014) }\end{array}$ & Almanya & $\begin{array}{l}\text { Kamu görevlilerinin sel } \\
\text { risk algısı ve sele karşı } \\
\text { koruyucu davranışları } \\
\text { arasındaki ilşkiyi } \\
\text { araştırmak }\end{array}$ & $\begin{array}{l}\text { Sele karşı algılanan hasarın ciddiyeti ve } \\
\text { alınması gereken ek önlemlerin ve } \\
\text { güvenliklerin artırılması düșüncesi sel risk } \\
\text { algısını artırmaktadır. }\end{array}$ \\
\hline $\begin{array}{l}\text { (Mendonca } \\
\text { ve Gullo, } \\
2020 \text { ) }\end{array}$ & Brezilya & $\begin{array}{l}\text { Yarı yapılandırmış } \\
\text { görüșme formu ile } \\
\text { halkın heyelan risk } \\
\text { algısını araştırmak }\end{array}$ & $\begin{array}{l}\text { İnsanlar genellikle heyelan tehlikesinin } \\
\text { farkındadırlar ve heyelan hakkında temel } \\
\text { bilgiye sahiptirler. Heyelan tehdidi insanları } \\
\text { fazla endișelendirmemektedir. İnsanlar } \\
\text { heyelan risklerini azaltmak için kendi } \\
\text { rollerinin de olduğunun farkında değildirler. }\end{array}$ \\
\hline $\begin{array}{l}\text { (Fernandez, } \\
\text { Tun, Okazaki, } \\
\text { Zaw ve Kyaw, } \\
\text { 2018) }\end{array}$ & $\begin{array}{l}\text { Yangon, } \\
\text { Myanmar }\end{array}$ & $\begin{array}{l}\text { Yangın, deprem ve } \\
\text { siklon risk algısını } \\
\text { etkileyen faktörleri } \\
\text { belirlememek }\end{array}$ & $\begin{array}{l}\text { İnsanların risk algısı afet türlerine göre } \\
\text { şekillenmektedir ve afet türlerine karşı risk } \\
\text { algılarını etkileyen faktörler değişmektedir. } \\
\text { Örneğin, afet tecrübesi yangın ve depreme }\end{array}$ \\
\hline
\end{tabular}




\begin{tabular}{|c|c|c|c|}
\hline & & & $\begin{array}{l}\text { karşı algılanan olasılı̆̆ı negatif ve anlamlı } \\
\text { olarak etkilerken, siklona karşı algılanan } \\
\text { olasılığı anlamlı olarak etkilememektedir. } \\
\text { Çocuk sahibi olma durumu depreme karşı } \\
\text { korku düzeyini pozitif ve anlamlı olarak } \\
\text { etkilerken, yangın ve siklona karşı korku } \\
\text { düzeyini anlamlı olarak etkilememektedir. }\end{array}$ \\
\hline $\begin{array}{l}\text { (Arias, } \\
\text { Bronfman, } \\
\text { Cisternas ve } \\
\text { Repetto, } \\
\text { 2017) }\end{array}$ & Iquique, Şili & $\begin{array}{lr}\text { Kıyı şeridinde } \\
\text { tehlikeye yakınlı ve } \\
\text { tsunami risk algısı } \\
\text { arasındaki } & \text { ilişkiyi } \\
\text { araştırmak } & \\
\end{array}$ & $\begin{array}{l}\text { Kıyı şeridine daha yakın yaşayan insanların } \\
\text { daha yüksek tsunami risk algısı vardır. Cinsiyet } \\
\text { değişkeni tsunami risk algısını anlamlı olarak } \\
\text { etkilememektedir. Sosyo-ekonomik düzeyi } \\
\text { yüksek insanlar daha yüksek tsunami risk } \\
\text { algısına sahiptir. }\end{array}$ \\
\hline $\begin{array}{l}\text { (Tobin, } \\
\text { Whiteford, } \\
\text { Jones, } \\
\text { Murphy, } \\
\text { Garren ve } \\
\text { Padros, } \\
\text { 2011) }\end{array}$ & Meksika & 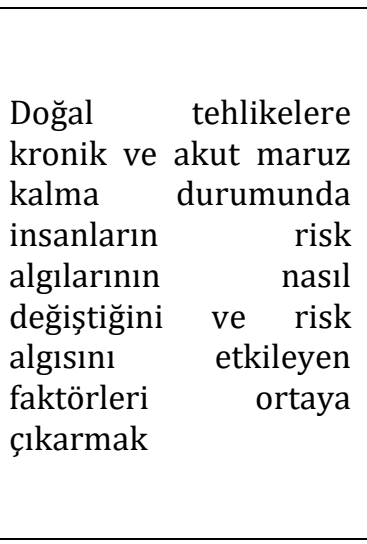 & $\begin{array}{l}\text { Bağımsız değişkenlerin volkanik patlama ve sel } \\
\text { risk algısı üzerindeki anlamlı etkisi } \\
\text { değişmektedir. Örneğin, insanların kas } \\
\text { problemleri, sonumum problemleri, genel } \\
\text { fiziksel şikayetleri, depresyon belirtileri ve } \\
\text { travma sonrası stres bozukluğu belirtileri } \\
\text { volkanik patlamaya karşı kendilerini daha fazla } \\
\text { tehlikede hissetmelerine neden olurken, sele } \\
\text { karşı kendilerini tehlikede hissetmelerine } \\
\text { neden olmamaktadır. Hane halkı durumunun } \\
\text { iyi olması volkanik patlamaya karşı endişe } \\
\text { düzeyini negatif ve anlamlı olarak etkilerken } \\
\text { sel endișesini etkilememektedir. }\end{array}$ \\
\hline $\begin{array}{l}\text { (Mızrak, } \\
\text { Özdemir ve } \\
\text { Aslan, 2021) }\end{array}$ & $\begin{array}{l}\text { Kocaeli, } \\
\text { Türkiye }\end{array}$ & $\begin{array}{l}\text { Kadınların deprem risk } \\
\text { algılarını etkileyen } \\
\text { faktörleri araştırmak }\end{array}$ & $\begin{array}{l}\text { Araştırmaya katılan kadınların çoğunluğu } \\
\text { kadın oldukları için kendilerini depreme karşı } \\
\text { daha hassas hissetmektedirler. Yaş kadınların } \\
\text { deprem risk algısını pozitif ve anlamlı olarak } \\
\text { etkiliyorken, eğitim kadınların deprem risk } \\
\text { algısını negatif ve anlamlı olarak } \\
\text { etkilemektedir. Kadınların depreme karşı } \\
\text { korkuları, depresyon durumları ve gelecekte } \\
\text { insanların depremden zarar görme } \\
\text { düşünceleri deprem risk algılarını pozitif ve } \\
\text { anlamlı olarak etkilemektedir. }\end{array}$ \\
\hline $\begin{array}{l}\text { (Tancogne- } \\
\text { Dejean ve } \\
\text { Laclémence, } \\
\text { 2016) }\end{array}$ & $\begin{array}{l}\text { Paris, } \\
\text { Fransa }\end{array}$ & $\begin{array}{l}\text { Yangın risk algısını } \\
\text { araştırmak }\end{array}$ & $\begin{array}{l}\text { Psikolojik, sosyal, fiziksel, kültürel ve çevresel } \\
\text { faktörler yaşlıların, engellilere hizmet veren } \\
\text { sağlık personelinin ve yangın tecrübesi olan } \\
\text { insanların risk algısını etkilemektedir. }\end{array}$ \\
\hline $\begin{array}{l}\text { (Domingues, } \\
\text { Jesus ve } \\
\text { Ferreira, } \\
\text { 2021) }\end{array}$ & Portekiz & $\begin{array}{l}\text { Yaşanılan yere bağlılık, } \\
\text { risk algısı ve hazırlık } \\
\text { arasındaki } \\
\text { araștırmak }\end{array}$ & $\begin{array}{l}\text { Yaşanılan yere bağlılık risk algısını } \\
\text { azaltmaktadır, afet tecrübesi risk algıı̆n } \\
\text { artırmaktadır ve risk algısı afet hazırlığını } \\
\text { azaltmaktadır. }\end{array}$ \\
\hline
\end{tabular}

\section{SONUÇ VE ÖNERÍLER}

Afet risk algısını etkileyen faktörler genel olarak veya herhangi bir afet türüne özel olarak yaygın bir şekilde çalışılmaktadır. Afet risk algısını etkileyen ve afet risk algısının etkilediği faktörlerin neler olduğu araștırılmaktadır. Afet yönetimi çalışmalarının etkili ve verimli bir şekilde planlanması ve afet sonrası afet planlarının başarılı bir şekilde uygulanabilmesi için toplumun afet yönetiminde daha güçlü bir katılımının bulunması gerekmektedir. Bu yüzden öncelikle insanların çevrelerinde hangi afet tehlikelerinin bulunduğu ve bu tehlikelerin etkisinin nasıl ve ne kadar olacağı belirlenmelidir. Özellikle, afet risk algısı çalışmaları afet yönetimi açısından çok önemlidir. 
Çünkü, afet risk algısı çalışmaları insanların afetler hakkındaki düşüncelerini ve afetlere yaklaşımlarını ortaya çıkarmaktadır.

İnsanların risk hakkındaki düşünceleri afetler ile ilgili hazırlıklarını ve afetlere karşı davranışlarını etkilemektedir. Toplumun afetlere karşı dirençli olması için doğru ve kapsamlı bir şekilde afetlerle mücadele etmesini etkileyen risk algılarını öğrenmek bilim insanlarının ve afet yöneticilerinin sorumluluğudur. $\mathrm{Bu}$ nedenle insanların her bir afet türüne karşı risk algıları sürekli olarak araștırılmalıdır. Risk algısını etkileyen faktörler ve risk algısının hangi davranışları nasıl ve ne kadar etkilediği belirlenmelidir. Özellikle meta analiz ve sistematik derleme çalışmaları ile afet türü ve risk algısı arasındaki ilişkiler daha derin bir şekilde araştırılabilir. Afetlerin özellikleri ve kapsamı farklı zamanlarda ve farklı bölgelerde değişebildiği için insanların afet risk algısı zamansal ve mekânsal olarak belirlenmelidir. Dahası, afet risk algısının zamansal ve mekânsal özelliklerinin hangi faktörlerden etkilendiği coğrafi bilgi sistemleri aracılığı ile görsel olarak sunulmalıdır.

\section{KAYNAKLAR}

Adelekan, I. O. ve Asiyanbi, A. P. (2016). Flood risk perception in flood-affected communities in Lagos, Nigeria. Natural Hazards, 80(1), 445-469. doi:10.1007/s11069-015-1977-2

Akar, S. (2013). Doğal afetlerin kamu maliyesine ve makro ekonomiye etkileri: Türkiye değerlendirmesi. Yönetim ve Ekonomi Araștırmaları Dergisi, (21), 185-206. doi:10.11611/JMER197

Arias, J. P., Bronfman, N. C., Cisternas, P. C. ve Repetto, P. B. (2017). Hazard proximity and risk perception of tsunamis in coastal cities: Are people able to identify their risk? PLoS ONE, 12(10), 1-14. doi:10.1371/journal.pone.0186455

Azimli Çilingir, G. ve Örçen Güler, İ. (2020). Afet politikalarında risk unsuru ve afet mevzuatında risk yönetimi. Uluslararası Yönetim Akademisi Dergisi, 3(1), 152-165. doi:10.33712/mana.687889

Bardsley, D. K., Moskwa, E., Weber, D., Robinson, G. M., Waschl, N. ve Bardsley, A. M. (2018). Climate change, bushfire risk, and environmental values: Examining a potential risk perception threshold in Peri-Urban South Australia. Society \& Natural Resources, 31(4), 424-441. doi:10.1080/08941920.2017.1421733

Beck, U. (2011). Risk toplumu: Başka bir modernliğe doğru (Çev. K. Özdoğan ve B. Doğan). İstanbul: İthaki Yayınları. (Orijinal yayın tarihi, 1992).

Becker, G., Aerts, J. C. J. H. ve Huitema, D. (2014). Influence of flood risk perception and other factors on riskreducing behaviour: A survey of municipalities along the Rhine. Journal of Flood Risk Management, 7(1), 16-30. doi:10.1111/jfr3.12025

Bourque, L. B., Regan, R., Kelley, M. M., Wood, M. M., Kano, M. ve Mileti, D. S. (2013). An examination of the effect of perceived risk on preparedness behavior. Environment and Behavior, 45(5), 615-649. doi:10.1177/0013916512437596

Bronfman, N. C., Cisternas, P. C., López-Vázquez, E. ve Cifuentes, L. A. (2016). Trust and risk perception of natural hazards: Implications for risk preparedness in Chile. Natural Hazards, 81(1), 307-327. doi:10.1007/s11069-015-2080-4

Bubeck, P., Botzen, W. J. W. ve Aerts, J. C. J. H. (2012). A review of risk perceptions and other factors that influence flood mitigation behavior. Risk Analysis, 32(9), 1481-1495. doi:10.1111/j.15396924.2011.01783.x 
Domingues, R. B., Jesus, S. N. de ve Ferreira, Ó. (2021). Place attachment, risk perception, and preparedness in a population exposed to coastal hazards: A case study in Faro Beach, southern Portugal. International Journal of Disaster Risk Reduction, 60. doi:10.1016/j.ijdrr.2021.102288

Donahue, A. K., Eckel, C. C. ve Wilson, R. K. (2014). Ready or not? How citizens and public officials perceive risk and preparedness. The American Review of Public Administration, 44(4_suppl), 89S-111S. doi:10.1177/0275074013506517

Fernandez, G., Tun, A. M., Okazaki, K., Zaw, S. H. ve Kyaw, K. (2018). Factors influencing fire, earthquake, and cyclone risk perception in Yangon, Myanmar. International Journal of Disaster Risk Reduction, 28, 140-149. doi:10.1016/j.ijdrr.2018.02.028

Gierlach, E., Belsher, B. E. ve Beutler, L. E. (2010). Cross-cultural differences in risk perceptions of disasters. Risk Analysis, 30(10), 1539-1549. doi:10.1111/j.1539-6924.2010.01451.x

Görüm, T. (2016). 23 Ekim 2011 Van depreminin tetiklediği heyelanlar. Türk CoğrafyDergísi, 66, 29-36. doi:10.17211/tcd.69854

Jóhannesdóttir, G. ve Gísladóttir, G. (2010). People living under threat of volcanic hazard in southern Iceland: Vulnerability and risk perception. Natural Hazards and Earth System Science, 10(2), 407-420. doi:10.5194/nhess-10-407-2010

Kalaycıoğlu, S. (2018). Afet sosyolojisi, sosyal riskler, sosyal kırılganlık. H. Şengün, S.Ç. Meydan Yıldız ve B. Tercan (ed.), Türkiye'nin Afet Yönetimi, Sosyal, Siyasal ve Yönetim Boyutuyla, (ss. 197-217), Palme Yayınevi, Ankara.

Kellens, W., Zaalberg, R., Neutens, T., Vanneuville, W. ve De Maeyer, P. (2011). An analysis of the public perception of flood risk on the Belgian Coast. Risk Analysis, 31(7), 1055-1068. doi:10.1111/j.15396924.2010.01571.x

Kung, Y.-W. ve Chen, S.-H. (2012). Perception of earthquake risk in Taiwan: Effects of gender and past earthquake experience. Risk Analysis, 32(9), 1535-1546. doi:10.1111/j.1539-6924.2011.01760.x

Liu, D., Li, Y., Shen, X., Xie, Y. ve Zhang, Y. (2018). Flood risk perception of rural households in western mountainous regions of Henan Province, China. International Journal of Disaster Risk Reduction, 27(2001), 155-160. doi:10.1016/j.ijdrr.2017.09.051

Liu, T., Zhang, H., Li, X. ve Zhang, H. (2020). Individual factors influencing risk perceptions of hazardous chemicals in China. Environmental Research, 186, 109523. doi:10.1016/j.envres.2020.109523

Math, S. B., Tandon, S., Girimaji, S. C., Benegal, V., Kumar, U., Hamza, A., ... Nagaraja, D. (2008). Psychological impact of the tsunami on children and adolescents from the Andaman and Nicobar islands. Primary Care Companion to the Journal of Clinical Psychiatry, 10(1), 31-37. doi:10.4088/pcc.v10n0106

Mendonca, M. B. de ve Gullo, F. T. (2020). Landslide risk perception survey in Angra dos Reis (Rio de Janeiro, southeastern Brazil): A contribution to support planning of non structural measures. Land Use Policy, 91, 104415. doi:10.1016/j.landusepol.2019.104415

Mizrak, S. ve Aslan, R. (2020). Disaster risk perception of university students. Risk, Hazards and Crisis in Public Policy, 11(4), 411-433. doi:10.1002/rhc3.12202

Mırak, S., Özdemir, A. ve Aslan, R. (2021). Adaptation of hurricane risk perception scale to earthquake risk perception and determining the factors affecting women's earthquake risk perception. Natural Hazards. doi:10.1007/s11069-021-04918-z

O’Neill, E., Brereton, F., Shahumyan, H. ve Clinch, J. P. (2016). The impact of perceived flood exposure on flood-risk perception: The role of distance. Risk Analysis, 36(11), 2158-2186. doi:10.1111/risa.12597 
Padhan, R. ve Prabheesh, K. P. (2021). The economics of COVID-19 pandemic: A survey. Economic Analysis and Policy, 70, 220-237. doi:10.1016/j.eap.2021.02.012

Prabhakar, S. V. R. K., Srinivasan, A. ve Shaw, R. (2009). Climate change and local level disaster risk reduction planning: Need, opportunities and challenges. Mitigation and Adaptation Strategies for Global Change, 14(1), 7-33. doi:10.1007/s11027-008-9147-4

Qasim, S., Nawaz Khan, A., Prasad Shrestha, R. ve Qasim, M. (2015). Risk perception of the people in the flood prone Khyber Pukhthunkhwa province of Pakistan. International Journal of Disaster Risk Reduction, 14, 373-378. doi:10.1016/j.ijdrr.2015.09.001

Renn, 0. (2004). Perception of risks. Toxicology Letters, 149(1-3), 405-413. doi:10.1016/j.toxlet.2003.12.051

Simonovic, S. P. (2011). Systems approach to management of disasters: methods and applications. New Jersey: John Wiley \& Sons.

Tancogne-Dejean, M. ve Laclémence, P. (2016). Fire risk perception and building evacuation by vulnerable persons: Points of view of laypersons, fire victims and experts. Fire Safety Journal, 80, 9-19. doi:10.1016/j.firesaf.2015.11.009

Tercan, B. (2018). Afetler ve yerleşim yeri değişiklikleri. H. Şengün, S.Ç. Meydan Yıldız ve B. Tercan (ed.), Türkiye'nin Afet Yönetimi, Sosyal, Siyasal ve Yönetim Boyutuyla, (ss. 161-194), Palme Yayınevi, Ankara.

Tobin, G. A., Whiteford, L. M., Jones, E. C., Murphy, A. D., Garren, S. J. ve Padros, C. V. (2011). The role of individual well-being in risk perception and evacuation for chronic vs. acute natural hazards in Mexico. Applied Geography, 31(2), 700-711. doi:10.1016/j.apgeog.2010.12.008

Trumbo, C. W., Peek, L., Meyer, M. A., Marlatt, H. L., Gruntfest, E., McNoldy, B. D. ve Schubert, W. H. (2016). A Cognitive-Affective scale for hurricane risk perception. Risk Analysis, 36(12), 2233-2246. doi:10.1111/risa.12575

URL 1, https: //www.undrr.org/media/48008/download (Son Erişim: 19.10.2020).

URL 2, https://www.unisdr.org/files/7817_UNISDRTerminologyEnglish.pdf (Son Erişim: 25.13.2021).

URL 3, https://www.unisdr.org/files/43291_sendaiframeworkfordrren.pdf (Son Erişim: 19.08.2021).

URL 4, https://www.afad.gov.tr/kurumlar/afad.gov.tr/e_Kutuphane/Planlar/AFAD-2019_2023STRATEJIK-PLAN.pdf (Son Erişim: 21.10.2021).

URL 5, https://irap.afad.gov.tr/upload/Node/42062/files/IRAP_KILAVUZ_tum_v8.pdf (Son Erișim: 19.10.2021).

URL 6, https://sozluk.gov.tr/ (Son Erişim: 15.06.2021).

URL 7, https://www.afad.gov.tr/aciklamali-afet-yonetimi-terimleri-sozlugu (Son Erişim: 25.10.2020).

URL 8, https://www.mevzuat.gov.tr/MevzuatMetin/1.5.6331.pdf (Son Erişim: 12.03.2021).

Xu, D., Liu, E., Wang, X., Tang, H. ve Liu, S. (2018). Rural households' livelihood capital, risk perception, and willingness to purchase earthquake disaster insurance: Evidence from Southwestern China. International Journal of Environmental Research and Public Health, 15(7), 1319. doi:10.3390/ijerph15071319

Xu, D., Yong, Z., Deng, X., Liu, Y., Huang, K., Zhou, W. ve Ma, Z. (2019). Financial preparation, disaster experience, and disaster risk perception of rural households in earthquake-stricken areas: Evidence from 
the Wenchuan and Lushan Earthquakes in China's Sichuan Province. International Journal of Environmental Research and Public Health, 16, 3345. doi:10.3390/ijerph16183345

Zhang, W., Wang, W., Lin, J., Zhang, Y., Shang, X., Wang, X., ... Ma, W. (2017). Perception, knowledge and behaviors related to typhoon: A cross sectional study among rural residents in Zhejiang, China. International Journal of Environmental Research and Public Health, 14(5), 492. doi:10.3390/ijerph14050492 